\title{
Some psychosocial and cultural factors in the Arab-Israeli conflict: a review of the literature
}

\author{
BENJAMIN BEIT-HALLAHMI ${ }^{1}$ \\ Institute for Human Adjustment, University of Michigan
}

This review is offered as an introductory guide to the literature on selected psychosocial and cultural aspects of the Arab-Israeli conflict. Its aims are to survey some of the scientific and nonscientific efforts that have been made to understand the psychosocial bases of behaviors in this conflict, and to clarify evidence related to major propositions regarding the impact of those bases. Its scope is limited by accepting the basic caveats of Kelman (1965a) and Etzioni (1969).

Kelman (1965a) makes clear that while we can use sociopsychological data to contribute to our understanding of a conflict, it cannot replace looking at the real issues and giving due regard to historical and political contexts. Etzioni (1969) suggests that sociopsychological knowledge can help clarify specific subproblems, but psychological studies cover only a segment of the behavior in international conflict.

Attempts to deal with the history and present status of the conflict from a psychological perspective can be classified into

\footnotetext{
'The author would like to express his thanks to the following individuals, who have helped in the preparation of this review: M. M. Beit-Hallahmi, J. D. Ben-Dak, J. E. Hofman, F. J. K'houri, D. Peretz, V. D. Sanua, S. R. Silverburg, H. H. Smythe, and G. R. Tamarin. Any errors or misconceptions are of course the author's sole responsibility.
}

three groups: psychological-theoretical (Liff, 1971; Tamarin, 1968a), psychological-empirical (Newnham, 1967; Sanua, 1970, 1971), and historical-ideological (Cohen, 1970; Deutscher, 1968; Harkabi, 1967a, 1968). This group of overviews was used as a source of propositions and hypotheses, and the following three issues were selected as the foci for this review: (1) cultural characteristics and "national character" as parameters in the conflict; (2) the internal function of external conflict as an impediment to solution on both sides; and (3) optimism and the uses of psychology in reaching for a resolution. It should be recognized that the review deals with a limited subset of psychosocial aspects, and not with the full range of psychosocial factors or specific issues in the conflict.

\section{Cultural Characteristics and}

\section{"National Character",}

\section{ARAB CULTURE AND PERSONALITY}

The idea that unique characteristics of the "Arab personality" or the Arab "national character" have affected the course of this conflict has been widely expressed. One implication of this idea is that we have to use an "Arab psychology" in order to explain the behavior of the Arab side in the conflict. Both implicitly and explicitly writ- 
ers dealing with the Arab "national character" have related their formulations to the conflict between the Arabs and the West in general, and between the Arabs and Israel in particular.

Sanua $(1970,1971,1966)$ is the major proponent of the Arab personality as a major factor in the conflict. Sanua's main contention is that ". . . the limitations of the Arab character have brought them (i.e. the Arabs) to their present predicament" (1970, p. 3). He provides the most comprehensive survey on the use of psychological instruments with Arab populations. His overview of the conflict is quite ambitious, trying to generalize from empirical studies with small groups to total Arab behavior vis-á-vis Israel. Sanua regards the Arab position as more rigid than the Israeli one, and therefore as the main obstacle to a resolution. This rigid position is seen as the result of specific Arab traits related to culture, language, and thought. His approach is limited by lack of consideration given to the other party in the conflict, namely the Israelis. Similarly Sanua considers psychological factors, and especially Arab characteristics, more important than the historical and political facts of the conflict.

A major Arab character trait, according to Sanua (1970) and others (Adams, 1957; Feldman, 1958; Gillespie and Allport, 1955), is extreme suspiciousness stemming from child rearing practices (cf. MacLeod, 1959) and directed towards fellow Arabs and foreigners alike. Sanua (1966) also presents conservatism and fatalism as major values in the culture of the Egyptian fellahin (cf. Racy, 1970).

Berger using personal observations described the interrelationship of hostility and politeness in Arab society in the following way: "Exaggerated hospitality and politeness are reactions to exaggerated hostility, at least in part . . . . Conflict is so much on the verge of breaking out that interpersonal relations seem to be largely directed at avoiding or covering up the slightest tendency towards the expression of difference" (1964, pp. 141-42). The thesis of "free floating hostility" in the Arab world may be used to explain Arab behavior in the conflict (Glidden, 1972). According to this thesis, hostility may be seen as a basic part of close interpersonal relationships in the Arab world, and not just the result of intergroup tension and specific conflicts.

While most of the sources cited above contain personal observations and anecdotal evidence, systematic psychological studies of Arabs were performed over the last twenty years by Prothro and Melikian (1952) and Melikan (1959b) at the American University of Beirut. Melikian (1956) and Prothro and Melikian (1953) described Arab culture as authoritarian, compared to the American culture. Comparing a group of American students to a group of students at the American University in Beirut, Melikian (1956) reported higher levels of authoritarianism and hostility in the Middle East group. Another comparison of American and Egyptian groups (Melikian, 1959a) showed similar results. Melikian (1959a) also suggested that in Egypt an authoritarian Moslem may be more "healthy" psychologically, because he is conforming to a general cultural pattern.

The concept of the "Arab imagination" or "lack of reality testing" is likely to be used quite often in discussions of the conflict, and especially its military aspects (Harkabi, 1967b). "Blurred" perception and "lack of distinction between truth and falsehood" were portrayed as Arab characteristics by Hamady (1960) and Hottinger (1963). Khatchadorian (1961) discussed the quality of "as if," which permeates Arab culture, and attributed this lack of genuineness to the traditions of ritual and authoritarianism, which created masks instead of men.

A personality type embodying all the al- 
leged faults of the Arab character from an Arab point of view is that of the "fahlawi." The fahlawi person (al-Azm, 1967) is superficial and vain in his approach to the tasks of reality. He constantly seeks the shortest way to success, glossing over problems and errors. According to al-Azm, it was the fahlawi mentality that played a role in Arab military defeats in 1967 . The fahlawi syndrome is related to what outside observers have termed "lack of reality testing" in Arab perceptions.

Sharabi recognizes the problem of Arab credibility as a major one and calls upon Arab leaders to go beyond what he calls "crude manipulation of facts" (1970, p. 1). He suggests a process whereby exaggeration and distortion are part of the feedback from recipients, which in turn reinforces any original tendency to distort. Avineri (1970) points out that a discussion of the "Arab imagination" has to deal with wider societal processes. We cannot discuss "reality testing" in this conflict without considering the realities to be tested. A full understanding of the Arab use of fantasy in this conflict has to consider not only cultural factors, but the value of fantasy as a functional solution. Needs and values emphasized by Glidden (1972) and Racy (1970) help us to view the use of imagination instead of reality testing as a solution to an impossible situation, in terms of Arab national self-concept. This solution may seem baffling and dysfunctional to Western observers, but it may be a most satisfying solution in the face of experienced helplessness and fatalism.

Related to the issues of Arab culture and personality is the nature of the Arabic language. Racy described Arabic as "particularly apt for affective and descriptive expression but not for precise or objective purposes"' (1970, p. 21). Shouby (1951) describes the effects of the Arabic language on patterns of thought and communication in the Arab world. The five characteristics of Arabic, according to Shouby, are vagueness; overemphasis on psychological significance of linguistic symbols at the expense of meaning; stereotyped emotional responses; overassertion and exaggeration; and two levels of life-ideal and real. All these are seen as related to Arab culture, religion, literature, and education.

The issue has been discussed by other writers, both Arabs and non-Arabs (Chejne, 1965; Harkabi, 1967b; Salem, 1958). Chejne (1965) points to the almost magical importance of the Arabic language in Arab politics, and its central role in Arab nationalism. Sanua (1966) has produced the most thorough review of the literature on the psychological properties of Arabic and their importance in interpersonal relations. He also considers the effects of Arabic to be among the causes of the present "impasse" in the conflict, and as one of the "limitations" of the Arabs (1970). Prothro (1955), in the only experimental work on the subject, supports the notion that Arabs are given to more overassertion in speech than Americans, but most of the writing on the psychological impacts of Arabic does not go beyond the impressionistic level.

One argument against the validity of most research on the "Arab personality" has to do with the populations studied. Most of the anecdotal reports are based on village populations, while most of the more systematic studies, such as those by Melikian and Prothro, deal with well-educated, modernized, and Westernized subjects. The problem of social change and modernization (Labban, 1960; Melikian, 1960) is added to that of representation. Reliance on the writer's personal observations and knowledge of popular literature (Hamady, 1960), however valuable, must be used with caution. When we are dealing with a rich folklore, such as that of the Arabs, it is possible to find proverbs that fit almost any charac- 
teristic or social situation. As we have seen, most writers agree on a number of characteristics, most of them quite negative.

Although several sources agree on the existence of suspiciousness as part of the Arab "national character," the question especially in the context of the Arab-Israeli conflict, is to explain its sources. Berger (1964) suggested that the arbitrary domination by local and foreign rulers over the centuries has contributed to the creation of a certain suspiciousness. Gardner (1959) commented on the Arab "inferiority feeling" resulting from centuries of foreign domination (cf. Racy, 1970). Arab suspiciousness regarding Israel can be well understood in this context: Being defeated repeatedly by a Western, technologically superior opponent, who seems to be very resourceful in finding new ways to humiliate them, and feeling victimized by stronger unknown outsiders are experiences which would contribute to clearly functional suspiciousness. In a situation where victimization and helplessness are the dominant experiences, it is better to be oversuspicious than let down one's guard. The connection between Israel and Western colonialism is not only historical and political but also psychological, since Israel brings back the same feelings of domination and helplessness.

Triandis (1971) came out against the whole concept of the "Arab personality," and suggested that societal patterns may be responsible for the behaviors attributed to the Arab basic personality structure. Another problem is the generality of the attributes supposedly unique to Arabs, since such attributes have been found to exist in other groups (including Israelis). Cohen (1970) points out one limitation of the emphasis on basic personality structure-its inability to account for cultural and historical changes. The issue surrounding the use of "modal personality" concepts in this case is that of efficiency. How helpful are con- cepts of basic personality structure in explaining and predicting national behavior of the actors in the conflict (cf. Terhune, 1970)? Given the lack of systematic analysis we may conclude that the issue is worth further exploration, and a clear presentation of conceptual steps from national character to national behavior is needed.

\section{ISRAELI CULTURE AND PERSONALITY}

Systematic studies of the "Israeli personality" or Israeli character traits, are even rarer than those dealing with its Arab counterpart (Sanua, 1971). One reason is the "melting pot" character of Israel. It is difficult to discuss an Israeli modal personality given the heterogeneity of Israeli society. A basic question, related to one of the central issues of the emerging Israeli identity (Herman, 1970), is that of the possible carryover of "Jewish traits" to the new "Israeli identity."

Some traits stemming from the Jewish history of being an oppressed minority were suggested in a psychoanalytic discussion of Jews by Loewenstein (1951). Among these are restlessness, a sense of inferiority, skepticism, and mistrust of Gentiles. Khouri (1971) described Israeli lack of trust as being as great as, or greater than, similar Arab feelings. Moreover he sees these feelings as directed not only towards the Arabs, but towards all outside powers. Rogers (1972) reports personal observations of suspiciousness and grandiosity in the Israeli position vis-á-vis the rest of the world. The grandiosity according to Rogers is expressed in the Israeli claims to rights that have a privileged status and transcend international law.

Rubinstein offers personal observations on the "Israeli psyche," stating: "As individuals and as a society, Israelis are characterized by a deeply rooted suspicious attitude toward others" (1971, p. 111). Suspiciousness according to Rubinstein permeates 
interpersonal relationships in Israel and spills over into every interaction with the outside world. He describes three levels of "distrust and rejection"-one directed against the non-Jewish world, one directed against the Arabs, and a third against "international machineries." Rubinstein thus agrees with the observations made by Khouri (1971) and Rogers (1971). Despite his lack of psychological sophistication, he describes an elaborate paranoid system related to the traditional distrust of Gentiles and to more recent suspicion of Arabs, which according to him has a major impact on Israeli policies and actions. An explanation similar to that presented above in connection with Arab suspiciousness seems to apply here. Thus being paranoid seems both prevalent and functional for all actors in this conflict, as in other international conflicts.

The basic posture towards outgroups and intergroup relations within Israeli society are intimately related to questions of identity as the following studies show. Mead (1958) contrasted the traditional Jewish identity with the developing Israeli identity. According to Mead what was always necessary to maintain Jewish identity was the larger outside group. "The only thing that was completely necessary to identify a group of Jews was to have some goyim" (p. 11). Mead found in Israel a "preoccupation with a continuing sense of identity, with Israel's unique mission, with Israel's position as different from that of any other people" (p. 20).

Herman (1970) agrees with Mead regarding the marking-off implications of the Jewish identity. He states that the division of the world between Jews and non-Jews is an essential implication of Jewish identity, and the image of the Gentile is central in the mind of the Jew. This demarcation from the Gentile world is still very much in effect in Israel while Arabs are serving only a limited marking-off function. The "Sabra" generation, Israeli-born Jewish residents of Israel, is described by Patai (1961) as having a unique identity. Its main characteristics are Israel-centeredness, in a spatial and temporal sense; lack of interest in recent Jewish history, even of their own parents; ambitions centered around material security and comfort; and unquestioned patriotism. Similar observations are reported by Rogers (1972) and Tamarin and Eisenberg (1969).

Israeliness and Jewishness are seen by Herman (1970) as two subidentities, which sometimes overlap. In Herman's sample of Israeli high school students and their parents the perception of overlap between these subidentities was reported by two-thirds of the respondents. However attitude towards Jewish religion turned out to be a significant modifier of the Jewish-Israeli overlap. When respondents were divided into religious, traditionalist and nonreligious, 41 percent of the nonreligious students saw no overlap between Jewishness and Israeliness. The religious dimension in Israeli identity was also analyzed by Hofman (1970). Empirically he found that the semantic space of identity concepts in Israeli high school students could be divided into a Jewish religious subarea and an Israeli secular subarea. Israelis could be classified on the basis of their identification with each subarea.

Dimensions that turn out to be significant in the measurement of Israeli identity structure also turn out to be the dimensions of potential and actual conflict and division in Israeli society. Two such dimensions are ethnic origin and religiosity. Tamarin (1968b, 1971a, 1971b) calls attention to the disruptive potential of these elements. Internal conflicts in Israel are described by Smythe and Weintraub, as involving "religion, language, culture, politics and race"' 1971, p. 17).

Similarly Herman (1970) describes the major divisions inside Israeli society as 
those between Oriental and European Jews, veteran settlers and new immigrants, and religious and nonreligious Jews. Peres (1971a) states that the tranquility in the relations between Orientals and Europeans in Israel is astonishing, given the social and economic gaps between the two groups. Social distance between Oriental and European Jews in Israel was found to be considerable and asymmetrical. Orientals expressed more readiness to accept Europeans, and social distance between Orientals from different countries of origin was larger than the distance between Europeans and Orientals (Peres, 1971a). These findings seem to parallel those by Hofman (1971), dealing with social distance between Israeli Jews and Arabs. Rim (1968) and Rim and Aloni (1969) found an essentially negative stereotype and self-stereotype of Orientals, compared to Europeans in Israel. This negative Oriental self-concept and the perceived European superiority appeared at an early age. Possible impacts of the forming Israeli identity and the present internal conflicts in Israel on the course of the wider conflict will become manifest in the next section.

\section{Sociopsychological Payoffs From the Conflict}

The permanence of the Arab-Israeli conflict has led to a series of sociopsychological adjustments paralleling the political and military ones.

Liff (1971) sees both Arabs and Israelis as reacting to an external threat in a way which prevents internal fragmentation, stagnation, inertia, and apathy. Accordingly “. . . the tension threai levels tend to be raised or lowered in a manner consistent with what each nation considers to be its own vital national interests"' (p. 9). Harkabi (1968) emphasized the importance of the conflict as a cohesive factor in several Arab states. According to him the salience of the conflict is greater in Jordan, since Jordanian society is only partially integrated and the conflict is being used by nationalist spokesmen to encourage integration. Another payoff of the conflict on the Arab side according to Harkabi (1968) is its contribution to the definition of the Arab identity. Hostility can help the formation of a national selfhood by negating the qualities ascribed to other nations. Cohen (1970) points to the use of anti-Israeli sentiment in the Arab world to conceal national disunity and promote pan-Arabism and Arab unity (cf. Diab, 1967).

The unifying effects of the conflict on internal subgroups in Israel were explained by Peres (1971a) in terms of three components: (1) interdependence of fate, as a national loss is perceived as a loss to all Israeli ethnic groups; (2) a common goal, since cooperation is perceived as necessary for survival; and (3) an outlet for aggression, as antagonistic impulses have a legitimate target. Newnham (1967) assumed similar payoffs for the Israeli side in the conflict. Religious circles in Israel may see a certain payoff in a continued conflict. Drori (quoted in Tamarin and Eisenberg, 1969), an Israeli religious spokesman, expresses the view that the constant conflict involves "many blessings," while a true peace involves the danger of "assimilation" and loss of Jewish "uniqueness." This may help to explain some positions taken by religious political parties in Israel.

Heightened cohesiveness as a result of external danger was one of the results of the 1967 crisis according to Herman (1970). Differences between Europeans and Orientals, religious and nonreligious, veterans and new immigrants were lessened as a result of the perceived threat. Similar observations regarding the effects of the 1967 war are reported by Rogers (1972). Harkabi (1967a) sees the continuous conflict as a source of strength and unity in Israel. He clearly im- 
plies that this payoff is one reason why Israel is not forced to seek a resolution. While admitting that Israel needs peace more than the Arabs, Harkabi claims that she can survive without it, and can gain strength until it comes.

Of special interest in this context are recent observations covering "disturbances" in the internal cohesion-external conflict model. Since the cease-fire of August 1970 a considerable decrease in the salience of experienced threat has been noticed in Israel. At the same time there has been a clear increase in expressions of internal intergroup tension. Demonstrations by Oriental groups organizing around claims of discrimination, wildcat strikes in considerable numbers and in public services, and a heightening of tensions between the religious and the secular segments-all signs of internal conflict-appeared with intensity during the first twelve months of the Suez cease-fire. These developments confirm the generalizations by Peres (1971a) and Harkabi (1967a) reported above. It would be wrong to assume that external conflict is the only thing holding Israel together, but it is clear that in the absence of external conflict internal divisions, described above, become prominent in Israeli society.

\section{Optimism and the Uses of Psychology}

\section{THE IMPACT OF MODERNIZATION}

Viewing the conflict as a clash between a traditional and a modern culture has been, for a wide range of writers (e.g., Patai, 1961), an easy way of conceptualizing it (Avirneri, 1970). The cultural gap between the Arabs and the Israelis has most often been mentioned as a factor in Arab military defeats (Zuraiq, 1967; Harkabi, 1967b). Viewing the Israeli-Arab differences as a result of a cultural gap led to the expectation that decreasing those differences would bring about a resolution of the conflict. It is important to spell out the assumptions involved in this line of reasoning.

The first assumption, universally accepted, is that Israel is more "modernized" or Westernized than the Arab countries. The second states that with changes in Arab society and the narrowing of the gap, militancy on the Arab side is likely to decline. The second assumption, as articulated by Israeli spokesmen (Ben-Gurion, 1968; Stock, 1968), sees the more modernized Arabs as better off, educationally and materially, and thus less frustrated. There is some naivete to this assumption, both psychologically and politically, but it has been espoused as almost official policy in Israel (Avineri, 1970). Implicit in this view are certain assumptions regarding the sources of Arab behavior in the conflict, namely generalized frustration and backwardness (cf. Sharabi, 1970).

The modernization hypothesis spelled out in terms of better education and a higher standard of living is central to expressed Israeli hopes for peace (cf. Ben-Gurion, 1971). Operationally, the prediction has been that as Arabs become more modernized, better educated (less religious?), and more advanced economically, they will be more compromising vis-á-vis Israel. Behind it was not only a hypothesis relating Arab behavior to various objective frustrations, but also another hypothesis relating more "rational" compromising behavior to modernization. Data on the effects of relative modernization on the attitudes of Israeli Arabs (Landau, 1969; Peres, 1971b) indicate clearly that these optimistic predictions have not been borne out by reality. Israeli Arabs acknowledge the role of the Israeli government in their modernization, and the necessity of acquiring modern technology (Peres, 1971b). At the same time increase in Arab nationalism is positively correlated with modernization. These findings indicate that the pacify- 
ing effects of modernization in the contact between Arabs and Israelis inside Israel are totally nonexistent.

The discussion of modernization and its hypothetical effects is related to the question of secularization as a force, affecting ideology and behavior in the conflict. The link of religion and ideology seems to be similar on both sides. Religious individuals and groups seem to hold extreme noncompromising positions (Harkabi, 1968; Tamarin, 1971a, 1971b). The role of religion in the ideological background of the conflict has been discussed more of ten in connection with the Arab side; its role in connection with the Israeli side has been discussed more recently, when basic Zionist assumptions have been analyzed (Harkabi, 1967a).

The seeming decline in the importance of religion, as measured by the decline in observance on the Israeli side (Herman, 1970), and in the decrease in discussions of the conflict in a religious context on the Arab side (Harkabi, 1968), may lead us to predict a related decrease in extremism. Just as in the case of modernization the realities of the conflict are different. A "turn to the right" seems to have taken place in Israel since the war of 1967 (Tamarin, 1971a, 1971b). The Israeli occupation of "holy places" seems to have driven home the basic religious-mystical message of Zionism (Harkabi, 1967a), and religious arguments are being used in favor of noncompromising positions (Rubinstein, 1971). On the Arab side the decline in the expressed religious significance of the conflict seems to be only partial. A unified "Moslem front" including such distant and noninvolved countries as Pakistan was formed around issues involving "holy places." At the same time genuinely nonreligious (i.e. Marxist) groups in the Arab world seem to be more noncompromising than ever in their opposition to Israel.

The apparent failure of the "moderniza- tion hypothesis" seems to rest on its limited use of psychological factors. Its one major implicit assumption appears to be that the Arab position in the conflict stems from Arab backwardness. Thus it ignores both the reality of the conflict and the psychological viability of the Arab position. While in this case optimism results from a limited use of psychology as an explanation, a wider use of psychology can lead to a more pervasive optimism, as the next section shows.

\section{THE "HUMAN RELATIONS" APPROACH}

A notable group of writers offering concrete suggestions towards resolution are the "human relations" advocates. The human relations approach sees the whole conflict as created by psychological factors, and therefore solved through psychological means. Lakin (1969) reports on two encounter groups conducted in Israel consisting of Jewish and Arab members. The rationale behind these groups is that expression of feelings and recognition of emotional reactions will decrease intragroup and intergroup Arab-Jewish conflict. Lakin recommends human relations training as a potential tool for Jewish-Arab cooperation, while Allen (1971) suggests group experiences including children from both sides. While we must respond to the sincerity of these attempts, good intentions are not enough and this case is no exception. Generalization from these group experiences is impossible since members were self-selected, having the prerequisite readiness for a dialogue (Benjamin, 1971). Other criticisms stem from the small scale of such attempts and the ambiguity of resulting changes in the participants.

In addition to the "planned change" attempts at resolution there were also expectations for a "natural" change in interaction between the two sides which would lead to a resolution. A natural potential for bridging the gap between the parties in conflict 
was found in two groups, by dint of their sharing in the traditions and motivations of both sides-the Israeli Arabs and the Oriental Jews in Israel. These two groups were considered natural candidates for "human relations" work in everyday contact. The present potential as stated by Peres (1971a) is rather meager; ". . . individuals who might have been the pioneers of integration under different circumstances became the most outspoken advocates of political hostility" (p. 62). These two groups of potential mediators are now the least motivated towards a reconciliation. The limitations of planned change and naturally expected change via the "human relations" approach are quite clear from the above presentation. Some of the implications of their psychological reductionism will be discussed below.

\section{Conclusion}

From these studies of sociopsychological factors in the Arab-Israeli conflict, what can we predict regarding the behavior of the actors? Can we predict or explain the development and possible resolution of the conflict any better than we could considering only political and economic factors? These questions lead us to two important recognitions-one regarding the general limitations of sociopsychological concepts in explaining the behavior of actors in international conflicts, and another regarding the specific limitations in coverage of the literature reviewed above.

Some psychosocial overviews of the conflict (e.g., Sanua, 1971; Glidden, 1972) illustrate the dangers of overemphasizing psychological aspects and thus psychologizing the conflict away. Psychological reductionism, in the form of viewing this conflict as caused by "psychological problems," "national character," or "irrationality" show the futility of one-factor theories or unidisciplinary approaches to social conflict.
The Israeli-Arab conflict is not a human relations problem in the narrow sense. Lakin quotes an anonymous Arab politician as saying "We do not need arms; we need psychiatrists" $(1969$, p. 1). The answer to this view of the conflict was given by Harkabi, who stated that "Arab hostility towards Israel was not created because of some psychological need to release tension or aggression" (1968, p. 111, translated from $\mathrm{He}$ brew).

Understanding the sociopsychological processes is necessary for a full and complete resolution but is not its basis. Given the reviews by Kelman (1965a, 1965b) and Etzioni (1969) it is easy to realize how limited is the literature in the case of the Arab-Israeli conflict. The literature reviewed offers many more untested hypotheses than empirical data.

If we try to determine the "rules of the game" for each of the actors in the conflict, one basis for such rules are the assumptions regarding the psychology of the other side. Such assumptions regarding the rationality and irrationality of the other actors are central to the positions of both sides. A cursory examination would suggest that both sides are inconsistent in their perceptions. For example in Israel the widely held opinion that "the Arabs understand only force" (assuming rationality) is replaced by claims regarding Arab "inability to learn" and "implacable hatred" (assuming irrationality), when it is realized that the Arab actors "have not learned their lesson" (Cohen, 1970). These processes and the ways they affect decision making and policies, such as deterrence or retaliation, have not been studied.

Suggestions for further areas of research seem almost unnecessary, since there is little coverage of any area. One neglected group in terms of available research is the Palestinians. Systematic studies of Palestinians are with rare exceptions (Bruhus, 1955; 
Dodd and Barakat, 1970) almost nonexistent. Paradoxically the best studies of Palestinians are of those under Israeli rule and of those living in Israel permanently (Hofman and Debbiny, 1970; Jiryis, 1968).

At the same time there are few attempts to assess the importance of psychological factors in the Israeli moves in the conflict. One example is language. While some writers deal with the presumed effects of Arabic on Arab behavior, no similar attention is paid to the usage of Hebrew in Israel, except for one clumsy attempt by Zweig (1969). A look at the writings of Israeli ideologists suggest the need for a careful study of the language, especially in view of the use of Old Testament references, messianic ideas, and a terminology of "mission" and "destiny" (Ben-Gurion, 1958; Baal-Theshuva, 1963; Davis, 1956).

If we consider the system of participants in this conflict at various levels of involvement, we are impressed with the dearth of psychosocial data covering them and the lack of differentiation among subgroups. There is little differentiation in the literature among subgroups in the Arab world, and lack of appreciation of the complexities of large subgroups on both sides (e.g., Oriental Jews in Israel and Palestinians in the Arab world).

One of the main priorities of future work should be the investigation of those differences among subgroups. Most of the approaches presented in this review were global and comprehensive. Any attempts at more specific and selective conceptualizations should help in determining how important any of the selected issues are in the future course and eventual resolution of this conflict.

\section{REFERENCES}

Adams, J. B. Culture and conflict in an Egyptian village, American Anthropologist, 1957, 59, $225-35$.
Al-Azm, S. J. Al-Ahad, Beirut, August 23 \& 30, 1967 (in Arabic).

Allen, D. T. Discussion, The International Psychologist, 1971, 12 (2, International Understanding suppl.), 31-33.

Avineri, S. Modernization and Arab society: some reflections. In R. I. Sinai (ed.), Modernization and the Middle East. New York: American Academic Association for Peace in the Middle East, 1970.

Baal-Theshuva, J. (ed.). The Mission of Israel. New York: Speller, 1963.

Ben-Gurion, D. David Ben-Gurion, In His Own Words. New York: Fleet Press, 1968.

$$
46 .
$$

Benjamin, A. On Arab-Jewish encounter groups. Second Haifa Conference on Research in ArabJewish Relations, Haifa University, Haifa, Israel, July 1971.

Berger, M. The Arab World Today. Garden City, N.Y.: Doubleday, 1964.

Bruhus, F. A study of Arab refugee attitudes, Middle East Journal, 1955, 9, 130-38.

Chejne, A. Arabic: its significance and place in Arab-Muslim society, Middle East Journal, 1965, 19, 447-70.

Cohen, A. Israel and the Arab World. New York: Funk and Wagnalls, 1970.

Davis, M. (ed.). Israel: Its Role in Civilization. New York: Jewish Theological Seminary, 1956.

Deutscher, I. The Non-Jewish Jew and Other Essays. London: Oxford University Press, 1968.

Diab, L. N. Measurement of social attitudes: problems and prospects. In C. W. Sherif and M. Sherif (eds.), Attitude, Ego-Involvement and Change. New York: Wiley, 1967.

Dodd, P. and H. Barakat. Palestinian refugees of 1967: a sociological study, Muslim World, $1970,60,123-42$.

Etzioni, A. Social psychological aspects of international relations. In $\mathrm{G}$. Lindzey and $\mathrm{E}$. Aronson (eds.), The Handbook of Social Psychology. Reading, Mass.: Addison-Wesley, 1969 , vol. 5.

Feldman, H. Children of the desert: notes on Arab national character, Psychoanalysis and the Psychoanalytic Review, 1958, 45, 40-50.

Gardner, G. The Arab Middle East: some background interpretations, Journal of Social Issues, $1959,15,20-27$.

Gillespie, J., and G. W. Allport. Youth Outlook on the Future. New York: Doubleday, 1955.

Glidden, H. The Arab world, American Journal 
of Psychiatry, 1972, 128, 984-88.

Hamady, S. Temperament and Character of the Arabs. New York: Twayne, 1960.

Harkabi, Y. Emdat Israel Be-Sikhsuhk IsraelArav (The Israeli Position in the Arab-Israeli Conflict). Tel-Aviv: Dvir, 1967a (in Hebrew). Basic factors in the Arab collapse during the Six Day War, Orbis, 1967b, 11, 677-91.

Emdat Ha-Aravim Besikhsukh IsraelArav (The Arab Position in the Arab-Israeli Conflict). Tel-Aviv: Dvir, 1968 (in Hebrew).

Herman, S. N. Israelis and Jews: The Continuity of an Identity. New York: Random House, 1970.

Hofman, J. E. The meaning of being a Jew in Israel: an analysis of ethnic identity, Journal of Personality and Social Psychology, 1970, 15, 196-202.

Readiness and perceived readiness for social relations between Arabs and Jews. Second Haifa University Conference on Research in Arab-Jewish Relations, Haifa, July 1971.

and S. Debbiny. Religious affiliation and ethnic identity, Psychological Reports, 1970, 26, 10-14.

Hottinger, A. The Arabs. London: Thames and Hudson, 1963.

Jiryis, S. The Arabs in Israel, 1948-1966. Beirut: Institute for Palestine Studies, 1968.

Khatchadorian, $\mathrm{H}$. The mask and the face, a study of "make-believe" in Middle East society, Middle East Forum, 1961, 37, 15-19.

Khouri, F. J. Personal communication, 1971.

Kelman, H. C. Social-psychological approaches to the study of international relations: definition of scope. In H. C. Kelman (ed.), International Behavior: A Social-Psychological Analysis. New York: Holt, 1965a.

Social-psychological approaches to the study of international behavior: the question of relevance. In H. C. Kelman (ed.), International Behavior: A Social-Psychological Analysis. New York: Holt, 1965b.

Labban, A. Towards a mature society, Middle East Forum, 1960, 36, 27-30.

Lakin, M. Arab and Jew in Israel: A Case Study in Human Relations Approach to Conflict. Washington, D.C.: NTL Institute, 1969.

Landau, J. M. The Arabs in Israel: A Political Study. London: Oxford University Press, 1969.

Liff, Z. A. The Arab-Israeli psychological impasse, The International Psychologist, 1971, 12, (2, International Understanding Suppl.), 3-13.

Loewenstein, R. M. Christians and Jews: A Psychoanalytic Study. New York: International
Universities Press, 1951.

MacLeod, R. B. The Arab Middle East: some social psychological problems, Journal of Social Issues, 1959, 15, 69-75.

Mead, M. Israel and Problems of Identity. New York: Theodore Herzl Foundation, 1958.

Melikian, L. H. Some correlates of authoritarianism in two cultures, Journal of Psychology, 1956, 42, 237-48.

Authoritarianism and its correlates in the Egyptian culture and the United States, Journal of Social Issues, 1959a, 15, 58-68.

Preference for delayed reinforcement: an experimental study among Palestinian Arab refugee children, Journal of Social Psychology, 1959b, 50, 81-87.

The dethronement of the father, Middle East Forum, 1960, 36, 23-25.

Newnham, J. D. Arab-Israeli relations: a pilot study of international attitudes, International Problems, 1957, 5, 81-90.

Patai, R. Cultures in Conflict. New York: Herzl Press, 1961.

Peres, Y. Ethnic relations in Israel. In M. Curtis (ed.), People and Politics in The Middle East. New Brunswick, N.J.: Transaction, 1971a.

Modernization and nationalism in the identity of the Israeli Arab. In G. C. Alroy (ed.), Attitudes Toward Jewish Statehood in the Arab World. New York: American Academic Association for Peace in the Middle East, $1971 b$.

and N. Yuval-Davis. Some observations on the national identity of the Israeli Arab, Human Relations, 1969, 22, 219-33.

Prothro, E. T. Arab-American differences in the judgment of written messages, Journal of Social Psychology, 1955, 42, 3-11.

and L. H. Melikian. Social distance and social change in the Near East, Sociology and Social Research, 1952, 37, 3-11.

The California public opinion scale in an authoritarian culture, Public Opinion Quarterly, 1953, 17, 353-62.

Racy, J. Psychiatry in the Arab East, Acta Psychiatrica Scandinavica, Supplementum, 1970, 211.

Rim, Y. Stereotipim leumiim etzel yeladim (Children's national stereotypes), Megamot, 1968, 16, 45-50 (in Hebrew).

and R. Aloni. Stereotypes according to ethnic origin, social class and sex, Acta Psychologica, 1969, 31, 312-25.

Rogers, R. R. The emotional climate in Israeli 
society, American Journal of Psychiatry, 1972, $128,988-92$.

Rubinstein, A. Why the Israelis are being difficult, The New York Times Magazine, April 18, 1971.

Salem, E. Form and substance: a critical examination of the Arabic language, Middle East Forum, 1958, 34, 17-19.

Sanua, V. D. The psychology of the Egyptian fellahin. Unpublished manuscript, 1966.

The national character of the Arabs and its effect on the Middle East conflict. American Psychological Association Annual Convention, Miami Beach, September 1970.

Is peace in the Middle East possible? A study of psychological factors, The International Psychologist, 1971, 12 (2, International Understanding suppl.), 14-29.

Sharabi, H. Palestine Guerrillas-Their-Credibility and Effectiveness. Beirut: Institute for Palestine Studies, 1970.

Shouby, E. The influence of the Arabic language on the psychology of the Arabs, Middle East Journal, 1951, 284-302.

Smythe, H., and S. Weintraub. Intergroup relations in Israel. In M. Curtis (ed.), People and Politics in the Middle East. New Brunswick, N.J.: Transaction, 1971.

Stock, E. From Conflict to Understanding: Relations between Arabs and Jews in Israel since
1948. New York: American Jewish Committee, 1968.

Tamarin, G. R. The Israeli-Arab conflict in terms of non-communication, New Outlook, 1968a, 11 (2), 8-23.

. Forms and foundations of Israeli theocracy. Tel-Aviv: Shikpul Press, 1968b (mimeo).

The Leap Forwards-Into the Past. Giwatayim, Israel: Monographs of the Institute for Socio-Psychological Research, 1971a (mimeo).

The Israeli Ethnic Landscape-An Extinguished Volcano? Giwatayim, Israel: Monographs of the Institute for Socio-Psychological Research, 1971b (mimeo).

and S. Eisenberg. Notebook pages on the theme of mixed marriage in Israel. Unpublished draft, Institute for Socio-Psychological Research, Giwatayim, Israel, 1969.

Terhune, K. W. From national character to national behavior: a reformulation, Journal of Conflict Resolution, 1970, 14, 203-63.

Triandis, H. C. Discussion, The International Psychologist, 1971, 12 (2, International Understanding suppl.), 30-31.

Zweig, F. Israel: The Sword and the Harp. London: Heinemann, 1969.

Zuraiq, C. Ma'ana al-Nakba Mujadadan (The Lesson of Disaster Renewed). Beirut, 1967 (in Arabic). 